University of Wollongong

Research Online

\title{
ISSFAL Official Statement Number 6: The importance of measuring blood omega-3 long chain polyunsaturated fatty acid levels in research
}

Renate H. M de Groot

Open University of the Netherlands

Barbara J. Meyer

University of Wollongong, bmeyer@uow.edu.au

Follow this and additional works at: https://ro.uow.edu.au/ihmri

Part of the Medicine and Health Sciences Commons

\section{Recommended Citation}

de Groot, Renate H. M and Meyer, Barbara J., "ISSFAL Official Statement Number 6: The importance of measuring blood omega-3 long chain polyunsaturated fatty acid levels in research" (2020). Illawarra Health and Medical Research Institute. 1519.

https://ro.uow.edu.au/ihmri/1519

Research Online is the open access institutional repository for the University of Wollongong. For further information contact the UOW Library: research-pubs@uow.edu.au 


\title{
ISSFAL Official Statement Number 6: The importance of measuring blood omega-3 long chain polyunsaturated fatty acid levels in research
}

\author{
Abstract \\ A statement on measuring blood omega-3 long chain polyunsaturated fatty acid levels was developed \\ and edited based on input from ISSFAL members and accepted by vote of the ISSFAL Board of Directors. \\ Summary of Statement: Omega-3 long chain polyunsaturated fatty acid (n-3 LCPUFA) levels at baseline \\ and post-intervention should be assessed and reported in future research to evaluate the efficacy of n-3 \\ LCPUFA supplementation: $b$ ecause; 1 . there are numerous factors that affect $n-3$ LCPUFA levels in \\ humans as described in the systematic literature review [1]; 2 . assessing intake of n-3 LCPUFA from the \\ diet and/or supplements is not sufficient to accurately determine n-3 LCPUFA levels in humans; 3 . some \\ studies do not provide sufficient doses of n-3 LCPUFA to produce a significant impact on bloodstream/ \\ organ content and there is substantial variability in the uptake of n-3 LPCUFA into tissues between \\ individuals. In secondary analyses, clinical trials should consider the influence of fatty acid status \\ (baseline, endpoint and change from baseline to endpoint) on the outcome variables.

\section{Disciplines} \\ Medicine and Health Sciences

\section{Publication Details} \\ de Groot, R. \& Meyer, B. J. (2020). ISSFAL Official Statement Number 6: The importance of measuring \\ blood omega-3 long chain polyunsaturated fatty acid levels in research. Prostaglandins Leukotrienes and \\ Essential Fatty Acids, 157 102029-1-102029-4.
}




\title{
ISSFAL Official Statement Number 6
}

\section{The importance of measuring blood omega-3 long chain polyunsaturated fatty acid levels in research}

\author{
Renate H. M. de Groot ${ }^{1}$ and Barbara J. Meyer ${ }^{2 *}$ \\ for the International Society for the Study of Fatty Acids and Lipids, ISSFAL \\ ${ }^{1}$ Faculty of Psychology and Educational Sciences, Welten Institute, Research Centre for Learning, \\ Teaching and Technology, Open University of the Netherlands, Valkenburgerweg 177, 6419AT, \\ Heerlen, the Netherlands. \\ ${ }^{2}$ School of Medicine, Lipid Research Centre, Molecular Horizons, University of Wollongong and \\ Illawarra Health \& Medical Research Institute, Northfields Ave, Wollongong, NSW 2522, Australia \\ * corresponding author \\ Professor Barbara J Meyer, \\ School of medicine, \\ University of Wollongong, \\ Northfields Ave, Wollongong, NSW 2522, Australia. \\ Email: bmeyer@uow.edu.au Phone: +61 (0)2 42213459 Fax: +61 (0)2 42218141 \\ A statement on measuring blood omega-3 long chain polyunsaturated fatty acid levels developed \\ and edited based on input from ISSFAL members and accepted by vote of the ISSFAL Board of \\ Directors.
}

\section{Summary of Statement}

Omega-3 long chain polyunsaturated fatty acid ( $n-3$ LCPUFA) levels at baseline and postintervention should be assessed and reported in future research to evaluate the efficacy of $n-3$ LCPUFA supplementation

Because:

1. There are numerous factors that affect $n-3$ LCPUFA levels in humans as described in the systematic literature review [1].

2. Assessing intake of $n-3$ LCPUFA from the diet and/or supplements is not sufficient to accurately determine $n-3$ LCPUFA levels in humans.

3. Some studies do not provide sufficient doses of n-3 LCPUFA to produce a significant impact on bloodstream/organ content and there is substantial variability in the uptake of $n-3$ LPCUFA into tissues between individuals. In secondary analyses, clinical trials should consider the influence of fatty acid status (baseline, endpoint and change from baseline to endpoint) on the outcome variables. 


\section{Introduction}

It is becoming increasingly clear that n-3 LCPUFA play an important role in human health [2]. N-3 LCPUFA have been shown to be important for neurological development $[3,4]$, cardiovascular health $[5,6]$ and there is emerging evidence of their beneficial role in other disease states, including mental health conditions [7].

Several mechanisms have been suggested for these potential health benefits [8], including effects on cell membranes which can influence signal transduction, promotion of neuronal growth, altering neurotransmitter release, and facilitating glucose uptake from the endothelial cells into the brain. $\mathrm{N}-3$ LCPUFA are also important precursors of the eicosanoids and docosanoids, which have antithrombotic and vasodilatory effects [8].

The evidence for the above-mentioned potential health benefits are derived from a large number of studies, including both epidemiological/observational studies and baseline data from randomised, controlled trials (RCT). However, many of these studies have failed to include measurements of $n-3$ LCPUFA levels. This may have serious implications for their ability to draw correct conclusions about the effects of omega- 3 on the measured outcome/s.

The recently published systematic literature review [1] highlights that there are many factors associated with the n-3 LCPUFA levels of an individual. Therefore, the aims of the current statement paper are to: 1. Recommend that researchers should measure n-3 LCPUFA levels at baseline and post-intervention, 2 . report on the full fatty acid results in future research and 3 . analyse the results as intention to treat, but also to analyse by the effect of the change of n-3 LCPUFA levels and the change in the outcome variable(s) where possible.

\section{Methods}

Professors Barbara Meyer and Renate de Groot proposed to the ISSFAL executive board to write a statement about the importance of measuring n-3 LCPUFA levels in research. After receiving a positive reply from the executive board and support from the ISSFAL board, the procedure for writing ISSFAL statements, as described on the ISSFAL website (http://www.issfal.org/statements/procedures-for-policy-statements), was followed. After a review by the ISSFAL Board, it became clear that a systematic review of factors associated with n-3 LCPUFA was necessary and has since been published [1]. This statement contains the summarised outcomes from the systematic literature review which focused on adults.

\section{Results of the evaluation}

\section{Terminology}

Various terminologies exist in the literature when describing n-3 LCPUFA levels (defined as n-3 PUFA not containing alpha-linolenic acid (ALA, 18:3n-3)) in an individual; including the Holman index; the Lands Highly Unsaturated Fatty Acids (HUFA) [9]; long chain omega-3 PUFA [10] and the HS-Omega-3 Index [11]. The $n-3$ LCPUFA levels are similar to the afore-mentioned terminologies, and hence $n-3$ LCPUFA levels are used in the current statement. 
The n-3 LCPUFA levels in an individual are associated with many factors including diet. It is welldocumented that dietary intake of n-3 LCPUFA is associated with n-3 LCPUFA levels $[12,13]$. However, dietary intake assessment is less reliable than measuring n-3 LCPUFA levels [14, 15]. The non-dietary factors that are associated with n-3 LCPUFA levels are identified in the systematic literature review [1] and these are listed in Table 1. The following factors have been found to be associated with n-3 LCPUFA levels through assessment of correlation studies and baseline data from RCT.

Results from the systematic literature review [1] showed that in general women had higher levels of DHA than men $[16,17]$. Studies regarding the genetic factors revealed that mutations in FADS1, FADS2 [18-23] and ELOVL2 [22, 23] resulted in lower levels of gamma-linolenic acid (GLA, 18:3n-6), arachidonic acid (AA, 20:4n-6), EPA, and DHA due to constraint(s) in the fatty acid metabolism pathway, however these constraint(s) may be overcome by supplementation with preformed EPA and DHA [24]. N-3 LCPUFA levels are positively associated with increased age [17, 25-47]. There is a negative association between participants' BMI and $n-3$ LCPUFA levels (erythrocyte EPA and DHA < $6 \%)[25,36,48-50]$, but not in individuals with a higher (> 6\%) erythrocyte EPA and DHA [34, 46, 5153]. Limited data suggests that waist girth $[25,43-45,49,50]$ and also the amount of physical activity $[46,51,52,54-58]$ is not associated with n-3 LCPUFA levels. There is a negative association with alcohol consumption and n-3 LCPUFA levels, especially when the beverage type is beer or spirit [43$45,59,60-64]$. Lower n-3 LCPUFA levels are found in smokers [25, 39, 43, 44, 51, 65-67]. Regarding bioavailability, there is no convincing evidence that krill oil is more bioavailable than fish oil $[68,69]$. There is no convincing evidence suggesting that the chemical form of $n-3$ LCPUFA supplements matters in terms of bioavailability [70,71]. With respect to the conversion of plant-derived n-3 fatty acids to n-3 LCPUFA there is some evidence that supplementation with ALA increases EPA but not DHA and high intakes of linoleic acid reduces the conversion of ALA to EPA (http://www.issfal.org/statement-5). Limited evidence suggests that stearidonic acid (SDA, 18:4n-3) supplementation increases EPA to a greater extent than supplementation with ALA, but SDA supplementation does not increase DHA levels [72].

The above findings support the statement that n-3 LCPUFA levels at baseline and post-intervention should be assessed and reported in future research to evaluate the effectiveness of $n-3$ LCPUFA supplementation.

Full fatty acids profiles are encouraged to be reported for the following reasons: (1) invariably people are looking at published data from a different perspective and with different goals in mind and the full composition is useful in many such ways; (2) it may also offer some quality control to see if the fatty acid profiles are consistent with other reports, especially since such data is often reported as a percentage so other fatty acid levels can affect the values in question; and (3) inspection can determine how extensive and complete was the identification of the fatty acids in a given tissue.

In summary, the factors that need to be taken into account when assessing the effect of $n-3$ LCPUFA include sex, age, BMI, alcohol consumption (and type of alcohol) and smoking.

[INSERT TABLE 1] 


\section{Conclusions}

1. Factors positively associated with the n-3 LCPUFA levels are: age, sex (women less than 50 years of age).

2. Factors negatively associated with the $n-3$ LCPUFA levels are: genetics, BMI (if erythrocyte EPA and DHA is less than 6\%), smoking and alcohol.

3. There is inconclusive evidence for the association of waist girth and physical activity with n-3 LCPUFA levels.

4. There is no convincing evidence that krill oil versus fish oil, or the chemical form of n-3 LCPUFA matters in terms of bioavailability.

5. It is unreliable to predict the n-3 LCPUFA levels in an individual according to food intake measured with food frequency questionnaires or comparable instruments.

\section{Recommendations}

The recommendations below are for people of all ages, however the systematic literature review [1] focussed on adults.

1. It is essential that in all types of research, including cross-sectional, cohort and clinical research, the n-3 LCPUFA levels are measured in biological samples, and this should be done according to appropriate study protocol. So, for cross-sectional studies the biological samples must be measured at one time point and for cohort and clinical intervention studies the biological samples must be measured at baseline and follow-up. Whether the biological samples should be, whole blood, plasma, or tissue, that is not the focus of this statement, however, there are algorithms available for data conversion [16]. Note that there are other publications for best practices for research in this field $[17,18]$.

2. In secondary analyses, researchers conducting clinical trials should consider the influence of fatty acid status on the outcome variables.

3. Lastly, publishing full fatty acid profiles (expressed both as percent of total fatty acids and as concentrations), rather than just n-3 LCPUFA, is highly recommended. 
Table 1: Various factors affecting n-3 LCPUFA levels. For further details, please refer to the systematic literature review [1].

\begin{tabular}{|c|c|c|c|}
\hline Factors & & Direction of association or comments & $\begin{array}{l}\text { Should take } \\
\text { factor into } \\
\text { account Yes } \\
\text { or No }\end{array}$ \\
\hline \multicolumn{4}{|l|}{$\begin{array}{l}\text { Unmodifiable } \\
\text { factors }\end{array}$} \\
\hline Sex & & $\begin{array}{l}\text { In general women have higher DHA levels } \\
\text { than men. }\end{array}$ & Yes \\
\hline Genetics & $\begin{array}{l}\text { FADS1 \& } \\
\text { FADS2 }\end{array}$ & $\begin{array}{l}\text { Negative association with GLA, AA, EPA, } \\
\text { and DHA levels. }\end{array}$ & \multirow{2}{*}{$\begin{array}{l}\text { No in } \\
\text { supplementation } \\
\text { trials }\end{array}$} \\
\hline & ELOVL2 & Negative association with DHA levels & \\
\hline Age & & $\begin{array}{l}\text { n-3 LCPUFA levels are positively } \\
\text { associated with age }\end{array}$ & Yes \\
\hline \multicolumn{4}{|l|}{ Modifiable factors } \\
\hline Body size & BMI & $\begin{array}{l}\text { Negative association between n-3 LCPUFA } \\
\text { levels and BMI in participants with } \\
\text { erythrocyte EPA and DHA }<6 \% \text {, but not in } \\
\text { individuals with erythrocyte EPA and DHA } \\
>7 \% \text {. }\end{array}$ & Yes \\
\hline & Waist girth & Inconclusive evidence. & No \\
\hline Physical activity & & Inconclusive evidence. & No \\
\hline Alcohol & & $\begin{array}{l}\text { Negative association between alcohol } \\
\text { consumption and } n-3 \text { LCPUFA levels. }\end{array}$ & $\begin{array}{l}\text { Yes, } \\
\text { Specification of } \\
\text { type and amount } \\
\text { of alcohol is highly } \\
\text { recommended }\end{array}$ \\
\hline Smoking & & $\begin{array}{l}\text { Negative association between smoking } \\
\text { and n-3 LCPUFA levels resulting in 6-17\% } \\
\text { lower n-3 LCPUFA erythrocyte EPA and } \\
\text { DHA in smokers. }\end{array}$ & Yes \\
\hline \multicolumn{4}{|l|}{$\begin{array}{l}\text { Bioavailability } \\
\text { factors }\end{array}$} \\
\hline $\begin{array}{l}\text { Different forms of } \\
\text { supplements }\end{array}$ & & There is no convincing evidence. & No \\
\hline $\begin{array}{l}\text { Krill oil versus fish } \\
\text { oil bioavailability }\end{array}$ & & No convincing evidence. & No \\
\hline
\end{tabular}




\section{References}

[1] R.H.M. de Groot, R. Emmett, B.J. Meyer, Non-dietary factors associated with n-3 long-chain PUFA levels in humans - a systematic literature review, Br J Nutr, 121 (2019) 793-808.

[2] P.C. Calder, P. Yaqoob, Omega-3 polyunsaturated fatty acids and human health outcomes, BioFactors, 35 (2009) 266-272.

[3] B.J. Meyer, C.C. Onyiaodike, E.A. Brown, F. Jordan, H. Murray, R.J. Nibbs, N. Sattar, H. Lyall, S.M. Nelson, D.J. Freeman, Maternal Plasma DHA Levels Increase Prior to 29 Days Post-LH Surge in Women Undergoing Frozen Embryo Transfer: A Prospective, Observational Study of Human Pregnancy, J Clin Endo Metab, 101 (2016) 1745-1753.

[4] M. Makrides, R.A. Gibson, Long-chain polyunsaturated fatty acid requirements during pregnancy and lactation, Am J Clin Nutr, 71 (2000) 307S-311S.

[5] GISSI Prevezione Investigators, Dietary supplementation with n-3 polyunsaturated fatty acids and vitamin E after myocardial infarction: results of the GISSI-Prevenzione trial, The Lancet, 354 (1999) 447-455.

[6] M. Yokoyama, H. Origasa, M. Matsuzaki, Y. Matsuzawa, Y. Saito, Y. Ishikawa, S. Oikawa, J. Sasaki, H. Hishida, H. Itakura, T. Kita, A. Kitabatake, N. Nakaya, T. Sakata, K. Shimada, K. Shirato, Effects of eicosapentaenoic acid on major coronary events in hypercholesterolaemic patients (JELIS): a randomised open-label, blinded endpoint analysis, The Lancet, 369 (2007) 1090-1098.

[7] N. Sinn, C. Milte, P.R. Howe, Oiling the brain: a review of randomized controlled trials of omega-3 fatty acids in psychopathology across the lifespan, Nutrients, 2 (2010) 128-170.

[8] N. Parletta, C.M. Milte, B.J. Meyer, Nutritional modulation of cognitive function and mental health, J Nutr Biochem, 24 (2013) 725-743.

[9] W.E.M. Lands, Biochemistry and physiology of n-3 fatty acids, FASEB J, 6 (1992) 2530-2536.

[10] B.J. Meyer, Are we consuming enough long chain omega-3 polyunsaturated fatty acids for optimal health?, Prostraglandins, Leukot, Essent Fatty Acids , 85 (2011) 275-280.

[11] W.S. Harris, C. Von Schacky, The Omega-3 Index: a new risk factor for death from coronary heart disease?, Prev Med, 39 (2004) 212-220.

[12] M. Swierk, P.G. Williams, J. Wilcox, K.G. Russell, B.J. Meyer, Validation of an Australian electronic food frequency questionnaire to measure polyunsaturated fatty acid intake, Nutr, 27 (2011) 641-646.

[13] M.A. Ingram, W. Stonehouse, K.G. Russell, B.J. Meyer, R. Kruger, The New Zealand PUFA semiquantitative food frequency questionnaire is a valid and reliable tool to assess PUFA intakes in healthy New Zealand adults, J Nutr, 142 (2012) 1968-1974.

[14] B.J. Meyer, M. Swierk, K.G. Russell, Assessing long-chain omega-3 polyunsaturated fatty acids: a tailored food-frequency questionnaire is better, Nutr, 29 (2013) 491-496.

[15] S.A.Bingham. Limitations of the various methods for collecting dietary intake data, Ann Nutr Metab 35 (1991) 117-127.

[16] S. Lohner, K. Fekete, T. Marosvölgyi, T. Decsi, Gender Differences in the Long-Chain Polyunsaturated Fatty Acid Status: Systematic Review of 51 Publications, Ann Nutr Metab, 62 (2013) 98-112.

[17] W.S. Harris, J.V. Pottala, S.A. Varvel, J.J. Borowski, J.N. Ward, J.P. McConnell, Erythrocyte omega-3 fatty acids increase and linoleic acid decreases with age: observations from 160,000 patients, Prostraglandins, Leukot, Essent Fatty Acids, 88 (2013) 257-263.

[18] M. Al-Hilal, A. Alsaleh, Z. Maniou, F.J. Lewis, W.L. Hall, T.A. Sanders, S.D. O'Dell, M.s. team, Genetic variation at the FADS1-FADS2 gene locus influences delta- 5 desaturase activity and LC-PUFA proportions after fish oil supplement, J Lipid Res, 54 (2013) 542-551.

[19] R.A. Mathias, C. Vergara, L. Gao, N. Rafaels, T. Hand, M. Campbell, C. Bickel, P. Ivester, S. Sergeant, K.C. Barnes, F.H. Chilton, FADS genetic variants and omega- 6 polyunsaturated fatty acid metabolism in a homogeneous island population, J Lipid Res, 51 (2010) 2766-2774. 
[20] L.G. Gillingham, S.V. Harding, T.C. Rideout, N. Yurkova, S.C. Cunnane, P.K. Eck, P.J. Jones, Dietary oils and FADS1-FADS2 genetic variants modulate [13C]alpha-linolenic acid metabolism and plasma fatty acid composition, Am J Clin Nutr, 97 (2013) 195-207.

[21] L. Schaeffer, H. Gohlke, M. Muller, I.M. Heid, L.J. Palmer, I. Kompauer, H. Demmelmair, T. Illig, B. Koletzko, J. Heinrich, Common genetic variants of the FADS1 FADS2 gene cluster and their reconstructed haplotypes are associated with the fatty acid composition in phospholipids, Hum Mol Genet, 15 (2006) 1745-1756.

[22] T. Tanaka, J. Shen, G.R. Abecasis, A. Kisialiou, J.M. Ordovas, J.M. Guralnik, A. Singleton, S. Bandinelli, A. Cherubini, D. Arnett, M.Y. Tsai, L. Ferrucci, Genome-wide association study of plasma polyunsaturated fatty acids in the InCHIANTI Study, PLoS Genet, 5 (2009) e1000338.

[23] A. Baylin, E. Ruiz-Naraez, P. Kraft, H. Campos, Alpha-linolenic acid, delta 6 desaturase gene polymorphism, and the risk of myocardial infarction, Am J Clin Nutr, 85 (2007) 554-560.

[24] A. Alsaleh, Z. Maniou, F.J. Lewis, W.L. Hall, T.A. Sanders, S.D. O'Dell, ELOVL2 gene polymorphisms are associated with increases in plasma eicosapentaenoic and docosahexaenoic acid proportions after fish oil supplement, Genes Nutr, 9 (2014) 362.

[25] W.S. Harris, J.V. Pottala, S.M. Lacey, R.S. Vasan, M.G. Larson, S.J. Robins, Clinical correlates and heritability of erythrocyte eicosapentaenoic and docosahexaenoic acid content in the Framingham Heart Study, Atherosclerosis, 225 (2012) 425-431.

[26] C.G. Walker, L.M. Browning, A.P. Mander, J. Madden, A.L. West, P.C. Calder, S.A. Jebb, Age and sex differences in the incorporation of EPA and DHA into plasma fractions, cells and adipose tissue in humans, Br J Nutr, 111 (2014) 679-689.

[27] M. Fortier, J. Tremblay-Mercier, M. Plourde, R. Chouinard-Watkins, M. Vandal, F. Pifferi, E. Freemantle, S.C. Cunnane, Higher plasma n-3 fatty acid status in the moderately healthy elderly in southern Quebec: higher fish intake or aging-related change in n-3 fatty acid metabolism?, Prostraglandins, Leukot, Essent Fatty Acids, 82 (2010) 277-280.

[28] D. Rees, E. Miles, T. Banerjee, S. Wells, C. Roynette, K. Wahle, P. Calder, Dose-related effects of eicosapentaenoic acid on innate immune function in healthy humans: a comparison of young and older men, Am J Clin Nutr, 83 (2006) 331-342.

[29] M. Vandal, E. Freemantle, J. Tremblay-Mercier, M. Plourde, M. Fortier, J. Bruneau, J. Gagnon, M. Begin, S.C. Cunnane, Plasma omega-3 fatty acid response to a fish oil supplement in the healthy elderly, Lipids, 43 (2008) 1085-1089.

[30] M. Plourde, R. Chouinard-Watkins, M. Vandal, Y. Zhang, P. Lawrence, J.T. Brenna, S.C. Cunnane, Plasma incorporation, apparent retroconversion and [beta]-oxidation of $13 \mathrm{C}$-docosahexaenoic acid in the elderly, J Nutr Metab, 8 (2011) 5.

[31] M. Hennebelle, A. Courchesne-Loyer, V. St-Pierre, C. Vandenberghe, C.-A. Castellano, M. Fortier, D. Tessier, S.C. Cunnane, Preliminary evaluation of a differential effect of an [alpha]-linolenate-rich supplement on ketogenesis and plasma [omega]-3 fatty acids in young and older adults, Nutr, 32 (2016) 1211-1216.

[32] K.S. Bjerve, K.J. Fougner, K. Midthjell, K. Bønaa, n-3 fatty acids in old age, J Intern Med, 731 (1989) 191-196.

[33] K. Kuriki, T. Nagaya, N. Imaeda, Y. Tokudome, N. Fujiwara, J. Sato, M. Ikeda, S. Maki, S. Tokudome, Discrepancies in dietary intakes and plasma concentrations of fatty acids according to age among Japanese female dietitians, Eur J Clin Nutr, 56 (2002) 524-531.

[34] T. Ogura, H. Takada, M. Okuno, H. Kitade, T. Matsuura, M. Kwon, S. Arita, K. Hamazaki, M. Itomura, T. Hamazaki, Fatty Acid Composition of Plasma, Erythrocytes and Adipose: Their Correlations and Effects of Age and Sex, Lipids, 45 (2010) 137-144.

[35] R. Otsuka, Y. Kato, T. Imai, F. Ando, H. Shimokata, Higher serum EPA or DHA, and lower ARA compositions with age independent fatty acid intake in Japanese aged 40 to 79, Lipids, 48 (2013) 719-727.

[36] S.A. Sands, K.J. Reid, S.L. Windsor, W.S. Harris, The impact of age, body mass index, and fish intake on the EPA and DHA content of human erythrocytes, Lipids, 40 (2005) 343-347. 
[37] R.H. de Groot, M.P. van Boxtel, O.J. Schiepers, G. Hornstra, J. Jolles, Age dependence of plasma phospholipid fatty acid levels: potential role of linoleic acid in the age-associated increase in docosahexaenoic acid and eicosapentaenoic acid concentrations, Br J Nutr, 102 (2009) 1058-1064. [38] Bolton-Smith C, Woodward M, Tavendale R, Evidence for age-related differences in the fatty acid composition of human adipose tissue, independent of diet, Eur J Clin Nutr, 51 (1997) 619-624. [39] R.C. Block, W.S. Harris, J.V. Pottala, Determinants of Blood Cell Omega-3 Fatty Acid Content, Open Biomark J, 1 (2008) 1-6.

[40] T. Kawabata, S. Hirota, T. Hirayama, N. Adachi, C. Hagiwara, N. Iwama, K. Kamachi, E. Araki, H. Kawashima, Y. Kiso, Age-related changes of dietary intake and blood eicosapentaenoic acid, docosahexaenoic acid, and arachidonic acid levels in Japanese men and women, Prostaglandins, leukotrienes, and essential fatty acids, 84 (2011) 131-137.

[41] F.L. Crowe, C.M. Skeaff, T.J. Green, A.R. Gray, Serum n-3 long-chain PUFA differ by sex and age in a population-based survey of New Zealand adolescents and adults, Br J Nutr, 99 (2008) 168-174. [42] L.C. Saga, K.H. Liland, R.B. Leistad, A. Reimers, E.O. Rukke, Relating fatty acid composition in human fingertip blood to age, gender, nationality and $n-3$ supplementation in the Scandinavian population, Int J Food Sci Nutr, 63 (2012) 790-795.

[43] E. Dewailly, C. Blanchet, S. Lemieux, S. Gingras, B.J. Holub, Cardiovascular disease risk factors and n-3 fatty acid status in the adult population of James Bay Cree., Am J Clin Nutr, 76 (2002) 85-92. [44] E. Dewailly, C. Blanchet, S. Gingras, S. Lemieux, L. Sauve, J. Bergeron, B.J. Holub, Relations Between n-3 Fatty Acid Status and Cardiovascular Disease Risk Factors Among Quebecers, Am J Clin Nutr, 74 (2001) 603-611.

[45] E. Dewailly, C. Blanchet, S. Lemieux, L. Sauve, S. Gingras, P. Ayotte, B.J. Holub, n-3 Fatty acids and cardiovascular disease risk factors among the Inuit of Nunavik, Am J Clin Nutr, 74 (2001) 464473.

[46] M. Itomura, S. Fujioka, K. Hamazaki, K. Kobayashi, T. Nagasawa, S. Sawazak, Y. Kirihara, T. Hamazaki, Factors influencing EPA plus DHA levels in red blood cells in Japan, In Vivo, 22 (2008) 131135.

[47] R. Tavendale, A.J. Lee, W.C. Smith, H. Tunstall-Pedoe, Adipose tissue fatty acids in Scottish men and women: results from the Scottish Heart Health Study, Atherosclerosis, 94 (1992) $161-169$.

[48] R. Cazzola, M. Rondanelli, S. Russo-Volpe, E. Ferrari, B. Cestaro, Decreased membrane fluidity and altered susceptibility to peroxidation and lipid composition in overweight and obese female erythrocytes, J Lipid Res, 45 (2004) 1846-1851.

[49] M. Micallef, I. Munro, M. Phang, M. Garg, Plasma n-3 Polyunsaturated Fatty Acids are negatively associated with obesity, Br J Nutr, 102 (2009) 1370-1374.

[50] P.R. Howe, J.D. Buckley, K.J. Murphy, T. Pettman, C. Milte, A.M. Coates, Relationship between erythrocyte omega-3 content and obesity is gender dependent, Nutrients, 6 (2014) 1850-1860. [51] A. Sala-Vila, W.S. Harris, M. Cofán, A.M. Pérez-Heras, X. Pintó, R.M. Lamuela-Raventós, M.-I. Covas, R. Estruch, E. Ros, Determinants of the omega-3 index in a Mediterranean population at increased risk for CHD, Br J Nutr, 106 (2011) 425-431.

[52] K. Kuriki, T. Nagaya, Y. Tokudome, N. Imaeda, N. Fujiwara, J. Sato, C. Goto, M. Ikeda, S. Maki, K. Tajima, S. Tokudome, Plasma concentrations of (n-3) highly unsaturated fatty acids are good biomarkers of relative dietary fatty acid intakes: A cross-sectional study, J Nutr, 133 (2003) 36433650.

[53] Z. Makhoul, A.R. Kristal, R. Gulati, B. Luick, A. Bersamin, D. O'Brien, S.E. Hopkins, C.B. Stephensen, K.L. Stanhope, P.J. Havel, B. Boyer, Associations of obesity with triglycerides and Creactive protein are attenuated in adults with high red blood cell eicosapentaenoic and docosahexaenoic acids, Eur J Nutr, 65 (2011) 808-817.

[54] K. Sumikawa, Z. Mu, T. Inoue, T. Okochi, T. Yoshida, K. Adachi, Changes in erythrocyte membrane phospholipid composition induced by physical training and physical exercise, Eur J Appl Physiol, 67 (1993) 132-137. 
[55] Andersson A, Sjodin A, Hedman A, Olsson R, Vessby B, Fatty acid profile of skeletal muscle phospholipids in trained and untrained young men, Am J Physiol Endocrinol Metab, 279 (2000) E744E751.

[56] T. Kamada, S. Tokuda, S. Aozaki, S. Otsuji, Higher levels of erythrocyte membrane fluidity in sprinters and long-distance runners, J Appl Physiol, 74 (1993) 354 - 358.

[57] A. Arsic, V. Vucic, J. Tepsic, S. Mazic, M. Djelic, M. Glibetic, Altered plasma and erythrocyte phospholipid fatty acid profile in elite female water polo and football players, Appl Physiol, Nutr Metab = Physiologie appliquee, nutrition et metabolisme, 37 (2012) 40-47.

[58] J. Tepsic, V. Vucic, A. Arsic, V. Blazencic-Mladenovic, S. Mazic, M. Glibetic, Plasma and erythrocyte phospholipid fatty acid profile in professional basketball and football players, Eur J Appl Physiol, 107 (2009) 359-365.

[59] N. Theret, J.M. Bard, M.C. Nuttens, J.M. Lecerf, C. Delbart, M. Romon, J.L. Salomez, J.C. Fruchart, The relationship between the phospholipid fatty acid composition of red blood cells, plasma lipids, and apolipoproteins., Metab, 42 (1993) 562 - 568.

[60] C. Alling, L. Gustavsson, A. Kristensson-Aas, S. Wallerstedt, Changes in Fatty Acid Composition of Major Glycerophospholipids in Erythrocyte Membranes from Chronic Alcoholics During Withdrawal, Scan J Clin Lab Invest, 44 (1984) 283-289.

[61] M. de Lorgeril, P. Salen, J.-L. Martin, F. Boucher, J. de Leiris, Interactions of wine drinking with omega-3 fatty acids in patients with coronary heart disease: a fish-like effect of moderate wine drinking, Am Heart J, 155 (2008) 175-181.

[62] R. di Giuseppe, M. de Lorgeril, P. Salen, F. Laporte, A. Di Castelnuovo, V. Krogh, A. Siani, J. Arnout, F.P. Cappuccio, M. van Dongen, M.B. Donati, G. de Gaetano, L. Iacoviello, I.P. European Collaborative Group of the, Alcohol consumption and $n-3$ polyunsaturated fatty acids in healthy men and women from 3 European populations, Am J Clin Nutr, 89 (2009) 354-362.

[63] B. Perret, J.B. Ruidavets, C. Vieu, B. Jaspard, J.P. Cambou, F. Terce, X. Collet, Alcohol consumption is associated with enrichment of high-density lipoprotein particles in polyunsaturated lipids and increased cholesterol esterification rate, Alcohol Clin Exp Res, 26 (2002) 1134-1140. [64] P. Simonetti, A. Brusamolino, N. Pellegrini, P. Viana, G. Clemente, C. Roggi, B. Cestaro, Evaluation of the Effect of Alcohol Consumption on Erythrocyte Lipids and Vitamins in a Healthy Population, Alcohol Clin Exp Res, 19 (1995) 517-522.

[65] J.A. Simon, J. Fong, J. Bernert, W. Browner, Relation of Smoking and Alcohol Consumption to Serum Fatty Acids, Am J Epidemiol, 144 (1996) 325-334.

[66] G.C. Leng, F.B. Smith, F.G.R. Fowkes, D.F. Horrobin, K. Ells, N. Morsefisher, G.D.O. Lowe, Relationship between Plasma Essential Fatty-Acids and Smoking, Serum-Lipids, Blood-Pressure and Hemostatic and Rheological Factors, Prostraglandins, Leukot, Essent Fatty Acids, 51 (1994) 101-108. [67] J.R. Hibbeln, K.K. Makino, C.E. Martin, F. Dickerson, J. Boronow, W.S. Fenton, Smoking, gender, and dietary influences on erythrocyte essential fatty acid composition among patients with schizophrenia or schizoaffective disorder, Biol Psych, 53 (2003) 431-441.

[68] S.M. Ulven, K.B. Holven, Comparison of bioavailability of krill oil versus fish oil and health effect, Vasc Health Risk Manag, 11 (2015) 511-524.

[69] K. Yurko-Mauro, J. Kralovec, E. Bailey-Hall, V. Smeberg, J.G. Stark, N. Salem, Jr., Similar eicosapentaenoic acid and docosahexaenoic acid plasma levels achieved with fish oil or krill oil in a randomized double-blind four-week bioavailability study, Lipids Health Dis, 14 (2015) 99.

[70] J.P. Schuchardt, A. Hahn, Bioavailability of long-chain omega-3 fatty acids, Prostraglandins, Leukot, Essent Fatty Acids, 89 (2013) 1-8.

[71] A.L. West, G.C. Burdge, P.C. Calder, Lipid structure does not modify incorporation of EPA and DHA into blood lipids in healthy adults: a randomised-controlled trial, Br J Nutr, 116 (2016) 788-797. [72] E.J. Baker, E.A. Miles, G.C. Burdge, P. Yaqoob, P.C. Calder, Metabolism and functional effects of plant-derived omega-3 fatty acids in humans, Prog Lipid Res, 64 (2016) 30-56.

[73] J.T. Brenna, M. Plourde, K.D. Stark, P.J Jones, Y.H. Lin, Best practices for the design, laboratory analysis, and reporting of trials involving fatty acids. Am J Clin Nutr 108, (2018) 211-227. 
[74] L.M. Browning, C.G. Walker, A.P. Mander, A.L. West, J. Madden, J.M. Gambell, S. Young, L Wang, S.A. Jebb, P.C. Calder, Incorporation of eicosapentaenoic and docosahexaenoic acids into lipid pools when given as supplements providing doses equivalent to typical intakes of oily fish. Am J Clin Nutr 96, (2012) 748-758.

[75] K.D. Stark, J.J. Aristizabal Henao, A.H. Metherel, L. Pilote, Translating plasma and whole blood fatty acid compositional data into the sum of eicosapentaenoic and docosahexaenoic acid in erythrocytes, Prostaglandins, leukotrienes, and essential fatty acids, 104 (2016) 1-10. 